\title{
MANAGEMENT IN PERIACETABULAR PELVIC CHONDROSARCOMA
}

doi: $10.2478 /$ rojost-2018-0072

Şt. Cristea, R. Popescu, Şt. Cuculici, M. Sava, R. Vișan, C. Zamfir

"Carol Davila" University of Medicine and Pharmacy, Bucharest, Romania; Orthopaedic Department, "Pantelimon" Emergency Hospital, Bucharest, Romania

The partial or complete excision of the hemipelvis with the sparing of the lower limb is an option of the treatment of pelvic chondrosarcomas and a therapeutic alternative of the interilio-abdominal disarticulation. The operation has the same indications as the interilio-abdominal disarticulation and offers a good solution for avoiding a mutilating operation.

A giant periacetabular pelvic chondrosarcoma developed in Ennequin zone II and partial zone III, was resected and reconstructed with iliofemoral cooptation after complex investigations - pelvic X-ray, CT, MRI, Bioptic confirmation.

The wide excision of the tumor, a stable reconstruction, and an efficient recovery are essential for a successful treatment of pelvic chondrosarcomas.

Keywords: pelvic chondrosarcomas, resection-reconstruction, interilio-abdominal disarticulation 